\title{
Driving Forces and Their Effects on Water Conservation Services in Forest Ecosystems in China
}

\author{
GONG Shihan ${ }^{1,2}$, XIAO Yang ${ }^{1,2}$, XIAO Yi ${ }^{1}$, ZHANG Lu ${ }^{1}$, OUYANG Zhiyun ${ }^{1}$ \\ (1. State Key Laboratory of Urban and Regional Ecology, Research Center for Eco-Environmental Sciences, Chinese Academy of Sci- \\ ences, Beijing 100085, China; 2. University of Chinese Academy of Sciences, Beijing 100049, China)
}

\begin{abstract}
Identifying the driving forces that cause changes in forest ecosystem services related to water conservation is essential for the design of interventions that could enhance positive impacts as well as minimizing negative impacts. In this study, we propose an assessment concept framework model for indirect-direct-ecosystem service (IN-DI-ESS) driving forces within this context and method for index construction that considers the selection of a robust and parsimonious variable set. Factor analysis was integrated into two-stage data envelopment analysis (TS-DEA) to determine the driving forces and their effects on water conservation services in forest ecosystems at the provincial scale in China. The results showed the following. 1) Ten indicators with factor scores more than 0.8 were selected as the minimum data set. Four indicators comprising population density, per capita gross domestic product, irrigation efficiency, and per capita food consumption were the indirect driving factors, and six indicators comprising precipitation, farmland into forestry or pasture, forest cover, habitat area, water footprint, and wood extraction were the direct driving forces. 2) Spearman's rank correlation test was performed to compare the overall effectiveness in two periods: stage 1 and stage 2 . The calculated coefficients were $0.245,0.136$, and 0.579 , respectively, whereas the tabulated value was 0.562 . This indicates that the driving forces obviously differed in terms of their contribution to the overall effectiveness and they caused changes in water conservation services in different stages. In terms of the variations in different driving force effects in the years 2000 and 2010, the overall, stage 1 , and stage 2 variances were $0.020,0.065$, and 0.079 in 2000 , respectively, and $0.018,0.063$, and 0.071 in 2010 . This also indicates that heterogeneous driving force effects were obvious in the process during the same period. Identifying the driving forces that affect service changes and evaluating their efficiency have significant policy implications for the management of forest ecosystem services. Advanced effectiveness measures for weak regions could be improved in an appropriate manner. In this study, we showed that factor analysis coupled with TS-DEA based on the IN-DI-ESS framework can increase the parsimony of driving force indicators, as well as interpreting the interactions among indirect and direct driving forces with forest ecosystem water conservation services, and reducing the uncertainty related to the internal consistency during data selection.
\end{abstract}

Keywords: driving effectiveness; driving force; factor analysis; forest ecosystem; two-stage data envelopment analysis; water conservation service

Citation: Gong Shihan, Xiao Yang, Xiao Yi, Zhang Lu, Ouyang Zhiyun, 2017. Driving forces and their effects on water conservation services in forest ecosystems in China. Chinese Geographical Science, 27(2): 216-228. doi: 10.1007/s11769-017-0860-3

\section{Introduction}

Since the publication of the United Nations Millennium Ecosystem Services Assessment (UNEP, 2005a; 2005b; 2005c; 2005d; 2005e), ecosystem services science has become a hot topic in ecology research in the twentyfirst century (Villa, 2012). Forest water conservation function is an important ecosystem service (Notter,

Received date: Accepted date:

Foundation item: Under the auspices of Science and Technology Service Network Initiative Project of the Chinese Academy of Sciences

(No. KFJ-EW-STS-002)

Corresponding author: OUYANG Zhiyun. E-mail: zyouyang@rcees.ac.cn

(C) Science Press, Northeast Institute of Geography and Agroecology, CAS and Springer-Verlag Berlin Heidelberg 2017 
2012) and an essential component of forest ecological function evaluations. Forests are considered as the most important ecosystems on land due to their conservation of soil water, groundwater recharge, and their runoff regulation effect (Krishnaswamy, 2013). Studies of forest ecosystem water conservation have considered the hydrological process of water conservation (Jetten, 1996; Asdak, 1998; Crockford, 2000; Nunez, 2006; Maes, 2009; Vose, 2011), estimating the conservation quantity and its spatiotemporal variation (Bosch, 1982; Brown, 2005; Farley, 2005; Sun, 2006; Mashayekhi, 2010), as well as the mechanisms related to the water conservation service function.

Human beings are among the primary causes of decreases in ecosystem service, but the factors that drive degradation remain largely unclear. Various hypotheses have produced rich arguments and several studies of the drivers of ecosystem service change were initiated in the late 1960s and early 1970s. Originally, some studies focused on simple causal analysis, such as religion (White, 1967), common property institutions (McCay and Jentoft, 1998), and capitalism and colonialism (O’Connor, 1988). However, ecosystem service change is not influenced by a single factor, but instead it is determined by multiple physical and biological drivers. Therefore, the focus on the mechanisms of ecosystem service change has gradually shifted from simple driver models to multiple driver couplings. The impacts-population-affluence-technology (IPAT) model is a representative multi-factor model that considers more than single causes (i.e., Impacts $=$ Population $\times$ Affluence $\times$ Technology), which emphasizes that there are multiple and interacting human drivers of environmental change, and their impacts are multiplicative rather than additive (Dietz, 1994). The IPAT model was first proposed to formalize the relationship between population, human welfare, and environmental impacts. For example, Waggoner and Ausubel (2002), and Chertow (2000) conducted empirical analyses based on its analytical elements. Palloni (1994) noted that population size can determine impacts but it is sometimes less important than other factors, while Stern (1998) focused on the effects of affluence on the environmental influence. Thus, the influences of multiple factors on the changes in ecosystem services and the mechanisms that underlie their interactions have been discussed in previous studies.
The ecosystem service assessment approach has been refined further by including factors such as specific sociopolitical, biophysical, and cultural drivers. The drivers of biodiversity loss in the empirical field as well as those of land use and cover changes have been tracked as main drivers of ecosystem service changes (Forester and Machlis, 1996; Geist and Lambin, 2002; Spangenberg, 2007; Jabbour, 2014). Similar to the variety of drivers considered in different studies, various frameworks are available for investigating driving forces, e.g., the driver-pressure-state-impact-response (DPSIR) scheme developed by the Organization for Economic Co-operation and Development. Many assessments have employed this approach, e.g., Kelble et al. (2013) proposed a conceptual model that merges the widely applied DPSIR conceptual model with ecosystem services, thereby obtaining a driver, pressure, state, ecosystem service, and response (DPSER) conceptual model, which replaced the 'impact' in DPSIR with 'ecosystem services'. Unlike the DPSIR model, which focuses on negative anthropomorphic impacts on ecosystems, the DPSER model incorporates both negative and positive changes in the ecosystems; thus, it represents the clear hierarchy of drivers by encompassing cause and effect.

Research into drivers has employed the full repertoire of methods, including quantitative (e.g., statistical model and simulation) and qualitative approaches, and the volume of studies is growing in terms of both size and sophistication (Rudel et al., 1996; Lambin et al., 2001). Based on 152 cases reported at the sub-national level and by analyzing the frequency of proximate causes and the underlying driving forces of deforestation, Geist and Lambin $(2001 ; 2002)$ concluded that tropical deforestation is driven by causal factor synergies, including economic factors, institutions, and national policies at local and regional scales. Structural equation modeling has been used to analyze the relationship between biodiversity loss based on socioeconomic and ecological factors (Forest, 1996).

In previous studies, different qualitative conceptual frameworks have been presented for drivers of ecosystem change. and analyses have considered the driving forces that underlie changes in ecosystem services, as well as developing indicators. Most studies have considered bioscience aspects, especially the driving forces of deforestation and biodiversity. Clearly, previous studies have three main weaknesses in terms of the di- 
versity of the driving forces considered and the effectiveness of these drivers. Firstly, few studies have investigated the social and economic driving forces, and there has been a lack of research into the main drivers of forest ecosystem water conservation service change. Secondly, few investigations have attempted to quantitatively identify and evaluate the effectiveness of the main drivers of change in forest ecosystem water conservation services. For example, due to the lack of any theoretical justification for weighting each component differently, the components are usually weighted equally in additive models. Thirdly, there have been no attempts to discuss or distinguish the effectiveness of the indirect, direct, and overall driving forces that affect change in forest ecosystem water conservation services.

In the following sections, factor analysis (FA) and two-stage data envelopment analysis (TS-DEA) models are first reviewed briefly, with a graphical illustration of their coupling. Next, we describe the models for identifying the driving forces of forest ecosystem service change, before calculating the overall and individual stage effectiveness of drivers of forest ecosystem service in China during 2000 and 2010. Finally, we give some conclusions based on our discussion of these results.

\section{Methods and Materials}

\subsection{Study area}

In this study, we focused on the dynamics of the effectiveness of forest water conservation and its driving forces in China during 2000 and 2010. The overall area considered was approximately $9600000 \mathrm{~km}^{2}$. The landscape of China varies significantly across its vast width, where the diverse landscape types and different hydrothermal conditions in the latitudinal, longitudinal, and vertical terrains have formed a complex natural and geographical environment. China has an abundance of forest resources with a great variety of biological species and vegetation types, which provide humans with a wealth of eco-products, wood products, and eco-cultural services. In China, the total forest area is 208 million ha and forest covers $21.67 \%$ of the total land area. The forest stock volume is $1.51 \times 10^{10} \mathrm{~m}^{3}$. The research units include 22 provinces, 5 autonomous regions, and $4 \mathrm{mu}-$ nicipalities according to the administrative boundaries. Hong Kong, Macao, and Taiwan were excluded from this study because appropriate data were not available.
Thus, 31 provincial administrative regions were analyzed as decision-making units (DMUs) for data envelopment analysis (DEA) in the study.

\subsection{FA as a major tool for identifying driver indi- cators}

This study comprised two processes: screening indicators and estimating the effectiveness of driving forces (Fig. 1).

A driver is any natural or human-induced factor that directly or indirectly causes a change in an ecosystem. Two processes were used to screen for indicators in order to estimate forest ecosystem water conservation services (Fig. 1). The procedures used for selecting indicators generally comprised qualitative and quantitative methods. The former approach involved selecting the variables according to ecosystem theory and ecosystem service changes. The latter was based on a statistical procedure, such as FA. This step related a large number of variables to an outcome measure in order to identify statistically significant factors.

The general indicator set was determined by collecting relevant studies and by consulting ecologists. The candidate indicators were then subtracted from the general indicators using availability and scalability criteria, and divided into two groups of factors. The first group comprised indirect driving forces, i.e., fundamental social processes such as human population dynamics or economic growth, which underpin the proximate causes and that operate either at the local level or that have an indirect impact on forest ecosystem water conservation at the national or global level. An indirect driver influences the decision-making process and operates more diffusely, often by altering one or more direct drivers, where its influence was established by understanding its effects on direct drivers. The other group comprised the direct driving forces, i.e., human activities or immediate actions at the local level, such as infrastructural extension, agricultural expansion, and ecological restoration. These drivers originated from intended land use and directly impacted forest cover. A direct driver directly affects ecosystem conditions and services, thereby unequivocally influencing ecosystem processes, and thus they could be identified and measured with differing degrees of accuracy. For example, to explain the distinction between indirect and direct driving forces, inappropriate economic growth may increase greenhouse gas 


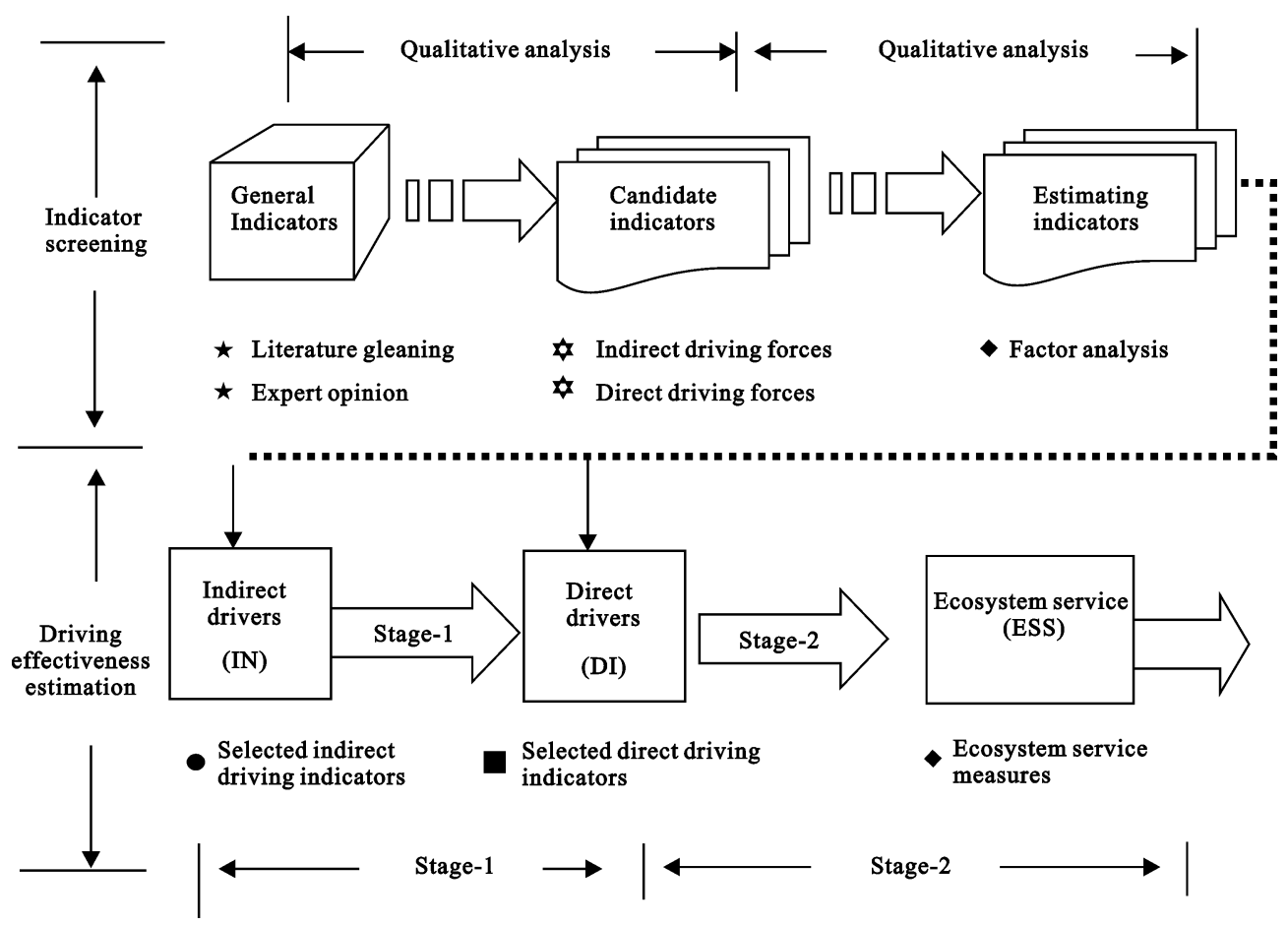

Fig. 1 Procedures for identifying indicators and estimating effectiveness of drivers. IN: indirect drivers; DI: direct drivers; ESS: ecosystem service

emissions, which are linked to climate change with predicted warmer temperatures and changes in precipitation. If climate change continues, extreme weather events will be more frequent, such as heat waves, floods, and droughts, as well as associated fires and pest outbreaks.

Indirect and direct driving forces were used to summarize the driving forces that underlie the variations in forest ecosystem water conservation services, which are defined as the capacity of ecosystems to hold part of the water input from precipitation at certain spatiotemporal scales. The interacting driving forces coupled with ecosystem services comprise an indirect-direct-ecosystem service (IN-DI-ESS) framework.

During the estimation of candidate indicators, it was necessary to reduce the number of indicators in order to satisfy the criteria for the number of DMUs vs. the numbers of inputs and outputs, i.e., the number of DMUS should be at least 2-3 times the combined number of inputs and outputs (Banker et al., 1989; Golany and Roll, 1989). We used 31 provincial administrative regions to estimate the effectiveness of driving force units, so we abstracted 10 or less variables for DEA.

FA can reduce the number of indicators, characterize the main information, and ensure the parsimony of the model. FA was used to identify the underlying structures and to minimize the number of indicators estimated in the final subset. A reduced number of variables were used to examine the socio-ecological and biophysical factors that contribute to forest ecosystem services.

\subsection{TS-DEA analysis for estimating effectiveness of drivers}

Suppose that a driving process comprises a series of two sub-processes, as depicted in Fig. 2.

The whole process uses $m$ inputs $X_{1 k}, i=1, \ldots, m$ to produce $s$ outputs $Y_{r k}, i=1, \ldots, s$, where the driving process is divided into two sub-processes with $q$ intermediate products $Z_{p k}, p=1, \ldots, q$, which differs from the conventional single stage driving process. Based on the constant return to scale DEA model (Charnes et al., 1978), the effectiveness scores for the two-stage process

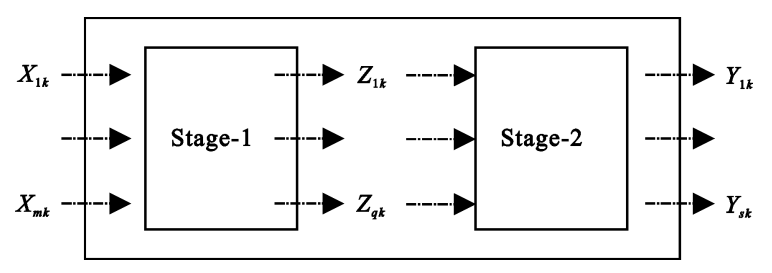

Fig. 2 Tandem driving force process with inputs $\mathrm{X}$, outputs $\mathrm{Y}$, and intermediate products $\mathrm{Z}$ 
and the two individual stages can be expressed as:

$E_{k}=\max \sum_{r=1}^{s} u_{r} Y_{r k}$

Subject to $\sum_{i=1}^{m} v_{i} X_{i k}=1$

$\sum_{r=1}^{s} u_{r} Y_{r j}-\sum_{i=1}^{m} v_{i} X_{i j} \leq 0, \quad j=1, \ldots, n$

$\sum_{p=1}^{q} w_{p} Z_{p j}-\sum_{i=1}^{m} v_{i} X_{i j} \leq 0, \quad j=1, \ldots, n$

$\sum_{r=1}^{s} u_{r} Y_{r j}-\sum_{p=1}^{q} w_{p} Z_{p j} \leq 0, \quad j=1, \ldots, n$

$u_{r} \geq \varepsilon, v_{i} \geq \varepsilon, w_{p} \geq \varepsilon, r=1, \ldots, s, i=1, \ldots, m$, $p=1, \ldots, q$,

where $X_{i j}(i=1, \ldots, m)$ and $Y_{r j}(r=1, \ldots, s)$ are the $i$ th input and $r$ th output of $D M U_{j}(j=1, \ldots, n)$, respectively, and we denote $Z_{p j}(p=1, \ldots, q)$ as the $p$ th intermediate product. We denote $u_{r}, v_{i}$ and $w_{p}$ as the multipliers of overall effectiveness $E_{k}$ and the sub-process effectiveness $E_{k}{ }^{1}$ and $E_{k}{ }^{2}$. The first stage effectiveness $E_{k}{ }^{1}$ can be solved while maintaining the overall efficiency score at $E_{k}$ based on Equation (1). This idea can be formulated as follows.

$E_{k}^{1}=\max \sum_{p=1}^{q} w_{p} Z_{p k}$

Subject to $\sum_{i=1}^{m} v_{i} X_{i k}=1$

$\sum_{r=1}^{s} u_{r} Y_{r k}-E_{k} \sum_{i=1}^{m} v_{i} X_{i k}=0$

$\sum_{r=1}^{s} u_{r} Y_{r j}-\sum_{i=1}^{m} v_{i} X_{i j} \leq 0, \quad j=1, \cdots, n$

$\sum_{p=1}^{q} w_{p} Z_{p j}-\sum_{i=1}^{m} v_{i} X_{i j} \leq 0, \quad j=1, \ldots, n$

$\sum_{r=1}^{s} u_{r} Y_{r j}-\sum_{p=1}^{q} w_{p} Z_{p j} \leq 0, \quad j=1, \ldots, n$

$u_{r} \geq \varepsilon, v_{i} \geq \varepsilon, w_{p} \geq \varepsilon, r=1, \ldots, s$,

$i=1, \ldots, m, p=1, \ldots, q$

After calculating $E_{k}{ }^{1}$ using the model above, the effectiveness of the second stage is obtained from the calculation as follows:

$$
E_{k}^{2}=E_{k} / E_{k}^{1}
$$

\section{Identification of Driving Force Indicators and Estimating Effectiveness of Drivers}

\subsection{Identification of driving force indicators 3.1.1 Constructing general indicator set}

In the first step, a literature review was performed to obtain a list of 53 variables considered in this study (Fig. 3). The general indicators were specified according to three criteria. The first was that the variables should be justifiable according to previous studies. The second was that the variables were available from national data sources, and the last was that variables should be scalable at different scales. Figure 3 presents an overview of the indicator systems taken from different sources. Four broad clusters of indirect causes were identified: demographic factors, economic factors, science and technology, and cultural and policy, where each category was further subdivided. Direct driving forces were categorized into five broad clusters: climate change, land use and cover, biodiversity, water use, and energy and resource extraction, where each was also subdivided into specific factors (Geist and Lambin, 2002; Spangenberg, 2007). Water use was considered in the water conservation index because we shifted the forest ecosystem water yield from supply to demand. Despite scientific and technological advances, as argued by Spangenberg (2014), the provision of ecosystem services is determined by human agencies and not ecosystem functions.

\subsubsection{Constructing candidate indicator set}

Table 1 shows the general indicator set comprising 30 variables from the 53 variables in the list (Fig. 3), which operationalized some of the more general concepts of ecosystem service change drivers. These variables were considered suitable for estimating the effects of driving forces according to the three conditions mentioned above. The list of 30 variables formed the candidate set used for further FA. In order to distinguish the mechanisms driving ecosystem service change, they were grouped into indirect drivers of 12 variables and direct drivers of 18 variables.

The indirect driving forces were obtained from the Statistical Yearbook of China (NBSC, 2001; 2011) and China Water Resources Bulletin (CMWR, 2001; 2011). The direct driving forces comprised climate change and variability, land use and cover, biodiversity, energy and 


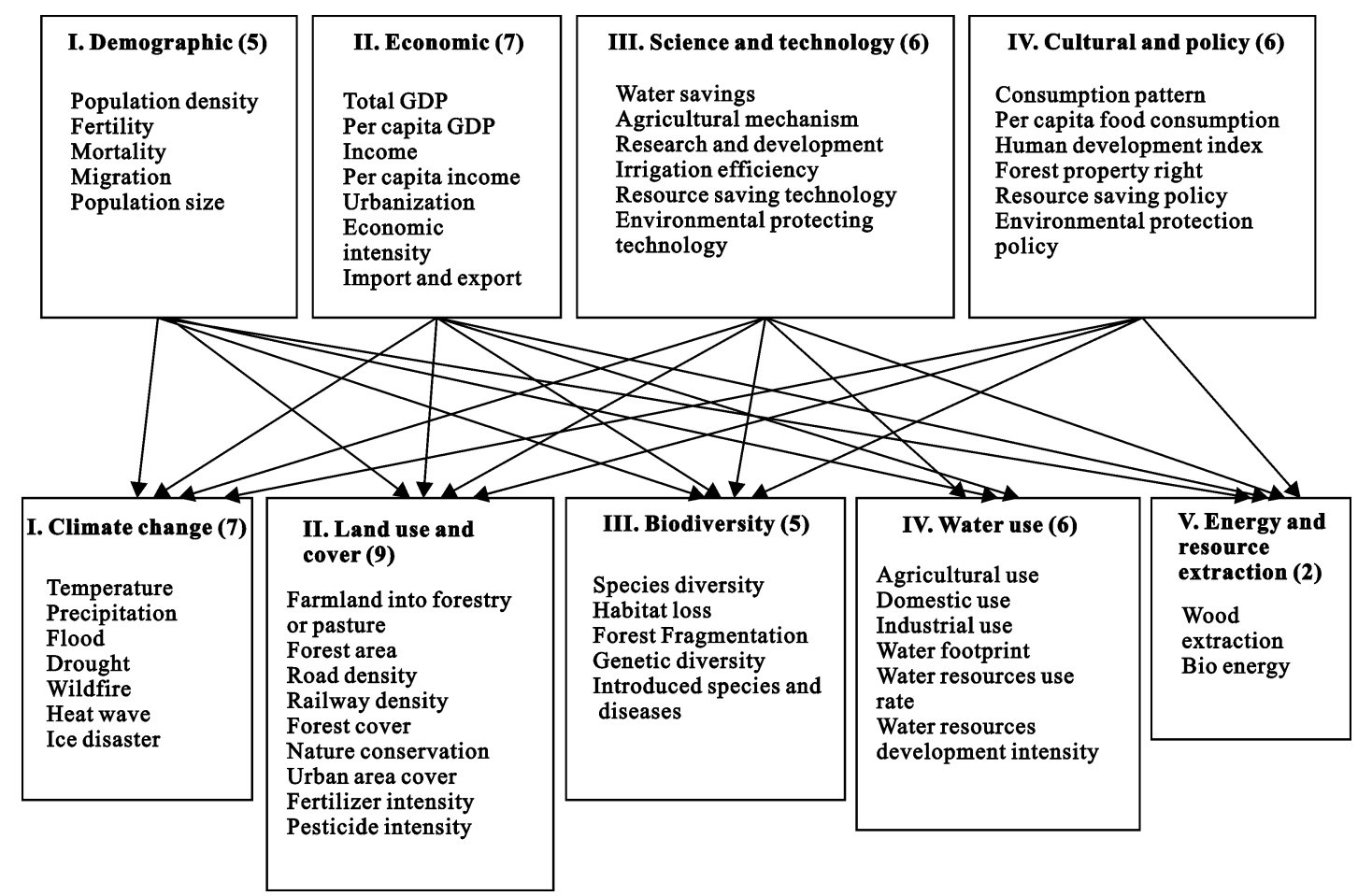

Fig. 3 Indirect and direct driving forces for forest water regulation services

resource extraction, and water use. The climate change variables considered as independent comprised the mean minimum temperature, mean maximum temperature, mean temperature, and precipitation. All of these variables were extracted from the digital climatic atlas of China with a pixel size of $500 \mathrm{~m} \times 500 \mathrm{~m}(\mathrm{http}: / / \mathrm{www}$. resdc.cn/) and the water-related disaster data were taken from the Bulletin of Flood and Drought Disaster in China (OSFCDRH, 2001; 2011). Land use and cover change data for China in 2000 and 2010 were obtained from the Resource and Environment Data Center of the Institute of Geographic Sciences and Natural Resources Research, Chinese Academy of Sciences. We used habitat areas and forest fragmentation to quantity the system diversity. Habitat areas and ecosystem service values were taken from the Research Report of Ecosystem Service and its Change during 2000 and 2010 in China, edited by the Research Center for Eco-Environmental Sciences, Chinese Academy of Sciences. Forest fragmentation selectively impedes the reproductive capacities of species that require a larger habitat, thereby shifting the balance of species and the state of the system. Considering both habitat areas and fragmentation indicates that the total area and its specific allocation are important. Introducing fragmentation and location as biodiversity specific policy criteria was a direct innovation. The reduction procedure is discussed in the following section.

\subsubsection{Constructing estimation indicator set}

FA and reliability analysis are often used in a complementary manner to explore whether the different dimensions of indexes are well-balanced (Nardo et $a l ., 2005 ; 2008)$. The reliability of the factor data was tested using Cronbach's alpha (Cronbach, 1951). The FA results (and reliability analysis) are presented in Table 1. Based on the results of principal components analysis, five factors were retained according to the Kaiser criterion (eigenvalue $>1$ ) and varimax rotation. Varimax rotation minimizes the number of variables that load highly on a single factor, which increases the percentage of variation between each factor. These five factors captured about $86 \%$ of the total variance in the 30 variables.

Factors with Cronbach's alpha values larger than 0.6 are considered reliable (Cronbach, 1951). Variables are usually identified in a factor if their loading on that factor is more than 0.7 , which ensures that the factor extracts sufficient variance from the variable. We selected a factor loading of 0.7 as a cutoff point because the factor loading represents the correlation coefficient, and 
Table 1 Indirect and direct driving force indicators for forest ecosystem water conservation services

\begin{tabular}{|c|c|c|c|c|c|c|c|}
\hline & Component & Indicator & Factor 1 & Factor 2 & Factor 3 & Factor 4 & Factor 5 \\
\hline \multirow{12}{*}{ 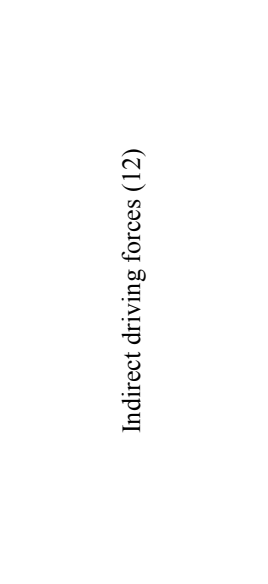 } & \multirow[t]{2}{*}{ I. Demographic factor } & Population density & 0.8914 & 0.5965 & 0.5670 & 0.3651 & 0.1733 \\
\hline & & Population size & 0.7725 & 0.4988 & 0.2237 & 0.5623 & 0.1466 \\
\hline & \multirow[t]{5}{*}{ II. Economic factor } & Total GDP & 0.35890 & 0.5171 & 0.5858 & 0.5590 & 0.1029 \\
\hline & & Per capita GDP & 0.9522 & 0.8848 & 0.3022 & 0.1738 & 0.4869 \\
\hline & & Per capita income & 0.5654 & 0.5943 & 0.3679 & 0.3552 & 0.1216 \\
\hline & & Urbanization & 0.6159 & 0.6023 & 0.7543 & 0.1353 & 0.0286 \\
\hline & & Economic intensity & 0.5671 & 0.2294 & 0.6815 & 0.3069 & 0.0304 \\
\hline & \multirow{3}{*}{$\begin{array}{l}\text { III. Scientific and } \\
\text { technical factor }\end{array}$} & Water savings & 0.3862 & 0.2984 & 0.4855 & 0.2019 & 0.4675 \\
\hline & & Agricultural mechanism & 0.7028 & 0.7943 & 0.5545 & 0.4926 & 0.3647 \\
\hline & & Irrigation efficiency & 0.6332 & 0.8749 & 0.3532 & 0.1109 & 0.2853 \\
\hline & \multirow{2}{*}{$\begin{array}{l}\text { IV. Cultural and } \\
\text { sociopolitical factor }\end{array}$} & Per capita food consumption & 0.6083 & 0.6556 & 0.0795 & 0.8807 & 0.5556 \\
\hline & & Human development index & 0.2560 & 0.4033 & 0.5151 & 0.7536 & 0.7278 \\
\hline \multirow{18}{*}{ 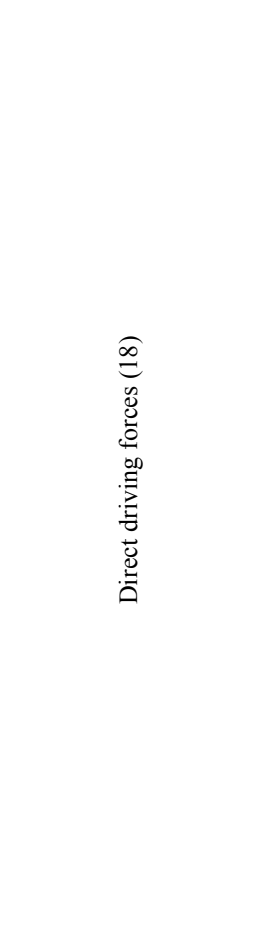 } & \multirow{5}{*}{$\begin{array}{l}\text { I. Climate change } \\
\text { and variability }\end{array}$} & Temperature & 0.7060 & 0.6054 & 0.1848 & 0.6992 & 0.5499 \\
\hline & & Precipitation & 0.8660 & 0.9502 & 0.5939 & 0.0606 & 0.7039 \\
\hline & & Flood & 0.7670 & 0.2662 & 0.5026 & 0.4893 & 0.7033 \\
\hline & & Drought & 0.6687 & 0.6480 & 0.5092 & 0.5891 & 0.4957 \\
\hline & & Wildfire & 0.6334 & 0.2485 & 0.6559 & 0.6137 & 0.0762 \\
\hline & \multirow[t]{6}{*}{ II. Land use and cover } & $\begin{array}{l}\text { Farmland into forestry } \\
\text { or pasture }\end{array}$ & 0.7834 & 0.9312 & 0.8768 & 0.2223 & 0.1442 \\
\hline & & Forest area & 0.7752 & 0.1942 & 0.5002 & 0.3122 & 0.2701 \\
\hline & & Road density & 0.3943 & 0.3870 & 0.1434 & 0.0966 & 0.1352 \\
\hline & & Railway density & 0.5801 & 0.2528 & 0.3916 & 0.4648 & 0.1718 \\
\hline & & Forest cover & 0.3578 & 0.3112 & 0.7669 & 0.0940 & 0.9590 \\
\hline & & Nature conservation & 0.5690 & 0.6812 & 0.7489 & 0.5086 & 0.6957 \\
\hline & \multirow[t]{3}{*}{ III. Biodiversity } & Species diversity & 0.2577 & 0.4131 & 0.4838 & 0.7863 & 0.2482 \\
\hline & & Habitat area & 0.6472 & 0.7386 & 0.1909 & 0.8203 & 0.9385 \\
\hline & & Forest fragmentation & 0.2683 & 0.3641 & 0.7299 & 0.7562 & 0.3169 \\
\hline & \multirow[t]{3}{*}{ IV. Water use } & Water footprint & 0.4740 & 0.1387 & 0.5065 & 0.8503 & 0.4579 \\
\hline & & Water resources use rate & 0.2109 & 0.3327 & 0.5979 & 0.3206 & 0.2217 \\
\hline & & $\begin{array}{l}\text { Water resources development } \\
\text { intensity }\end{array}$ & 0.1839 & 0.5574 & 0.4948 & 0.3739 & 0.2377 \\
\hline & $\begin{array}{l}\text { V. Energy and resource } \\
\text { extraction }\end{array}$ & Wood extraction & 0.7510 & 0.3844 & 0.7000 & 0.9880 & 0.6143 \\
\hline Variance (\%) & & & 17.68 & 19.76 & 15.87 & 15.64 & 17.86 \\
\hline Cumulative variance $(\%)$ & & & 17.68 & 37.44 & 53.31 & 68.95 & 86.81 \\
\hline Cronbach's alpha & & & 0.826 & 0.745 & 0.762 & 0.746 & 0.856 \\
\hline
\end{tabular}

Note: Factor loadings greater than 0.8 are shown in boldface type and selected indicators are also in boldface letters

thus at least $49 \%$ of the variance in the variable must be explained by the factor to which it belongs (Verma, 2013). According to variable number constraints when solving the DEA model on a per component basis, this was accomplished by selecting all factor scores $\geq 0.8$ and $\leq-0.8$. The factors that did not satisfy these two threshold levels were considered orphans and listed in the respective tables but excluded from further analyses.
Based on the loadings of individual variables in each factor, four variables (population density, per capita gross domestic product (GDP), irrigation efficiency, and per capita food consumption) and six variables (precipitation, farmland into forestry or pasture, forest cover, habitat area, water footprint, and wood extraction) were retained in the final solution, which were used as inputs in the subsequent two-stage DEA analysis. 


\subsection{Effectiveness of indirect and direct driving} forces

A positive directionality was assigned to all factors known to increase effectiveness, whereas a negative directionality was assigned to all factors known to decrease effectiveness. In the latter case, we replaced a component with its inverse, thereby allowing the final dimension to be subtracted from the overall effectiveness index. All the factors were fed into the DEA to obtain relative effectiveness scores. By applying Equations (1) and (2), we calculated the overall effectiveness and those for stage 1 and stage 2 (Table 2).

Table 2 Effectiveness and the ranks of indirect and direct drivers for forest ecosystem water conservation service change in 31 Provincial administrative regions in China

\begin{tabular}{|c|c|c|c|c|c|c|c|c|c|c|c|c|}
\hline \multirow{3}{*}{$\begin{array}{l}\text { Provincial } \\
\text { administrative } \\
\text { regions }\end{array}$} & \multicolumn{6}{|c|}{2000} & \multicolumn{6}{|c|}{2010} \\
\hline & \multicolumn{2}{|c|}{ Overall } & \multicolumn{2}{|l|}{ Stage 1} & \multicolumn{2}{|c|}{ Stage 2} & \multicolumn{2}{|l|}{ overall } & \multicolumn{2}{|c|}{ Stage 1} & \multicolumn{2}{|c|}{ Stage 2} \\
\hline & Effectiveness & Rank & Effectiveness & Rank & Effectiveness & Rank & Effectiveness & Rank & Effectiveness & Rank & Effectiveness & Rank \\
\hline Beijing & 0.1265 & 13 & 0.2830 & 14 & 0.4472 & 16 & 0.2196 & 7 & 0.2451 & 22 & 0.8958 & 3 \\
\hline Tianjin & 0.0491 & 26 & 0.1336 & 27 & 0.3672 & 21 & 0.0748 & 22 & 0.6900 & 5 & 0.1084 & 31 \\
\hline Hebei & 0.1032 & 19 & 0.2655 & 15 & 0.3888 & 19 & 0.1781 & 12 & 0.7723 & 4 & 0.2305 & 18 \\
\hline Shanxi & 0.1384 & 9 & 0.2955 & 13 & 0.4684 & 15 & 0.2356 & 5 & 0.3305 & 18 & 0.7130 & 6 \\
\hline Inner Mongolia & 0.0475 & 27 & 0.0481 & 31 & 0.9879 & 2 & 0.4278 & 2 & 0.3640 & 17 & 1.0000 & 1 \\
\hline Liaoning & 0.3765 & 3 & 0.4410 & 9 & 0.8536 & 5 & 0.6305 & 1 & 0.7900 & 3 & 0.7981 & 4 \\
\hline Jilin & 0.0332 & 28 & 0.2364 & 16 & 0.1403 & 27 & 0.0554 & 24 & 0.2730 & 21 & 0.2029 & 22 \\
\hline Heilongjiang & 0.0187 & 30 & 0.1136 & 28 & 0.1650 & 26 & 0.0312 & 27 & 0.1606 & 27 & 0.1944 & 25 \\
\hline Shanghai & 0.1017 & 20 & 1.0000 & 1 & 0.1017 & 31 & 0.1754 & 13 & 1.0000 & 1 & 0.1754 & 27 \\
\hline Jiangsu & 0.1042 & 18 & 0.1429 & 26 & 0.7296 & 7 & 0.1733 & 14 & 0.5732 & 10 & 0.3023 & 14 \\
\hline Zhejiang & 0.1353 & 10 & 0.3111 & 12 & 0.4350 & 18 & 0.2256 & 6 & 0.9594 & 2 & 0.2352 & 16 \\
\hline Anhui & 0.1171 & 14 & 0.4957 & 8 & 0.2362 & 23 & 0.0200 & 30 & 0.1410 & 29 & 0.1419 & 28 \\
\hline Fujian & 0.1283 & 12 & 0.2168 & 20 & 0.5921 & 12 & 0.2148 & 8 & 0.4584 & 12 & 0.4686 & 8 \\
\hline Jiangxi & 0.1392 & 8 & 0.1685 & 22 & 0.8260 & 6 & 0.2365 & 4 & 0.4366 & 14 & 0.5418 & 7 \\
\hline Shandong & 0.3134 & 4 & 0.7107 & 5 & 0.4410 & 17 & 0.0559 & 23 & 0.3103 & 19 & 0.1803 & 26 \\
\hline Henan & 0.2468 & 5 & 0.5244 & 7 & 0.4706 & 13 & 0.0421 & 26 & 0.2080 & 26 & 0.2024 & 23 \\
\hline Hubei & 0.0850 & 22 & 0.2195 & 19 & 0.3871 & 20 & 0.1422 & 16 & 0.6618 & 6 & 0.2148 & 20 \\
\hline Hunan & 0.1156 & 15 & 0.1627 & 23 & 0.7105 & 8 & 0.1939 & 10 & 0.5797 & 9 & 0.3345 & 13 \\
\hline Guangdong & 0.1322 & 11 & 0.1972 & 21 & 0.6705 & 9 & 0.0226 & 29 & 0.1034 & 30 & 0.2184 & 19 \\
\hline Guangxi & 0.1095 & 17 & 0.1095 & 30 & 1.0000 & 1 & 0.1833 & 11 & 0.4284 & 15 & 0.4279 & 11 \\
\hline Hainan & 0.1137 & 16 & 0.9709 & 2 & 0.1171 & 30 & 0.2000 & 9 & 0.4554 & 13 & 0.4392 & 10 \\
\hline Chongqing & 0.0797 & 23 & 0.3873 & 10 & 0.2057 & 24 & 0.1397 & 17 & 0.6028 & 7 & 0.2318 & 17 \\
\hline Sichuan & 0.4907 & 2 & 0.5573 & 6 & 0.8804 & 4 & 0.0833 & 21 & 0.2416 & 23 & 0.3448 & 12 \\
\hline Guizhou & 0.0753 & 24 & 0.1607 & 24 & 0.4687 & 14 & 0.1329 & 18 & 0.2858 & 20 & 0.4649 & 9 \\
\hline Yunnan & 0.6690 & 1 & 0.7409 & 4 & 0.9030 & 3 & 0.1124 & 19 & 0.1536 & 28 & 0.7320 & 5 \\
\hline Tibet & 0.2190 & 6 & 0.3657 & 11 & 0.5987 & 11 & 0.3690 & 3 & 0.3690 & 16 & 1.0000 & 1 \\
\hline Shaanxi & 0.0277 & 29 & 0.1568 & 25 & 0.1769 & 25 & 0.0477 & 25 & 0.2376 & 24 & 0.2008 & 24 \\
\hline Gansu & 0.1444 & 7 & 0.2355 & 17 & 0.6133 & 10 & 0.0246 & 28 & 0.2221 & 25 & 0.1110 & 30 \\
\hline Qinghai & 0.0149 & 31 & 0.1129 & 29 & 0.1317 & 29 & 0.0003 & 31 & 0.0019 & 31 & 0.1335 & 29 \\
\hline Ningxia & 0.0578 & 25 & 0.2199 & 18 & 0.2629 & 22 & 0.1050 & 20 & 0.4947 & 11 & 0.2122 & 21 \\
\hline Xinjiang & 0.1013 & 21 & 0.7498 & 3 & 0.1351 & 28 & 0.1724 & 15 & 0.5888 & 8 & 0.2927 & 15 \\
\hline Mean & 0.1489 & & 0.3462 & & 0.4810 & & 0.1590 & & 0.4238 & & 0.3790 & \\
\hline Variance & 0.0200 & & 0.0650 & & 0.0790 & & 0.0180 & & 0.0630 & & 0.0710 & \\
\hline
\end{tabular}




\subsubsection{Overall effectiveness of driving forces and in two stages in 2000}

It was notable that none of the 31 provinces, municipalities, and autonomous regions (referred to simply as regions in the following) had adequate effectiveness in all stages during 2000, which was demonstrated by the overall scores for all the regions, where the highest score was 0.6690 for Yunnan, followed by 0.4907 and 0.3765 for Sichuan and Liaoning, respectively. For stage 1, three regions had relatively high effectiveness: Shanghai, Hainan, and Xinjiang. For stage 2, three other regions had high effectiveness: Guangxi, Inner Mongolia, and Yunnan. Most regions had greater effectiveness in stage 2 than stage 1, except for Shanghai, Anhui, Shangdong, Henan, Hainan, Chongqing, and Xinjiang. Wilcoxon's matched-pairs signed-rank test (Daniel, 1978) confirmed that the effectiveness of stage 1 was lower than that of stage 2. Thus, the low effectiveness score of the overall impact process was positively correlated with the low effectiveness score of the indirect dynamic process.

The overall effectiveness is always less than or equal to the effectiveness of the corresponding stages, so there is little benefit to be obtained from examining the effectiveness scores themselves. By contrast, it is more informative to consider the ranks of the effectiveness scores (Table 2). Most regions had similar ranks in terms of their overall effectiveness and effectiveness in stages 1 and 2, thereby indicating that the overall effectiveness could be attributed equally to the effectiveness of the two sub-processes. However, several regions exhibited large differences in terms of these ranks. A large difference indicated the source of ineffectiveness for the whole process. For example, Inner Mongolia, Jiangsu, Jiangxi, Hunan, and Guangdong had less effectiveness in stage 1 compared with stage 2, whereas Jilin, Shanghai, Shandong, Anhui, Hainan, and Xinjiang had less effectiveness in stage 2 compared with stage 1 . Decomposing the overall effectiveness into the product of two components helped to identify the sub-process responsible for the ineffectiveness for a region. Logically, the rank of overall effectiveness for a region should lie either between the ranks of those in stages 1 and 2, or in their neighborhoods, because the effect of the overall process comprises the aggregated effectiveness of the two sub-processes. Among the 31 regions, the overall effectiveness ranks for 15 regions were between their ranks in stages 1 and 2, while the remainder were in the neighborhood of stages 1 and 2, which agreed with our intuitive expectation.

\subsubsection{Overall effectiveness of driving forces and in two stages in 2010}

Table 2 shows the results for the effectiveness of drivers in 2010. Three regions were effective in the overall driving process: Inner Mongolia, Liaoning, and Tibet. Surprisingly, none of them were effective in both sub-processes, which differed from the rationale of the relational model. Among the three regions, Liaoning had similar effectiveness in both sub-processes, whereas Inner Mongolia and Tibet were more effective in stage 2 than stage 1 . In terms of the sub-process of the indirect driving mechanism, Shanghai, Zhejiang, and Liaoning were ranked first, second, and third, respectively. However, for the sub-process of driving ecosystem and service change, Inner Mongolia and Tibet had a maximum effectiveness score of 1 , while Beijing also obtained a score of 0.8958 , which were significantly higher scores than those for the other regions.

The overall effectiveness is the product of the effectiveness in stages 1 and 2, so the overall scores could not exceed the effectiveness in the corresponding stages. The averages of these three measures validated the formulation (Table 2). We found that the average region had an overall score of 0.159 , thereby indicating that this region would be able to produce more than six times as much if it used its inputs efficiently. The average overall driving effectiveness was slightly higher than the score of 0.1489 in 2000, so this also implies the urgent need for Chinese ecosystem management. However, it should be mentioned that the overall effectiveness can only explain the general trend in the driving effect. For specific regions, analyzing the driving effectiveness for individual stages is important for ecosystem management. Table 2 shows that the mean driving effectiveness scores in stage 1and stage 2 were 0.4238 and 0.379 , respectively, which indicates that there were minor differences in the relative driving effectiveness in stage 1 compared with stage 2. This result suggests that forest ecosystem service management policy-makers should first focus on improving direct drivers and then proceed to improve the indirect drivers associated with direct drivers.

\subsubsection{Changes in the effectiveness of driving forces} from 2000 to 2010

By comparing the dynamics of the driving effectiveness 
from 2000 to 2010, we found that some regions performed effectively in stage 1 (e.g., Shanghai in 2000) or stage 2 (e.g., Inner Mongolia and Tibet in 2010), but their overall efficiency was not ranked highly. Wilcoxon's test showed that there was no significant difference between the overall effectiveness and that in stage 1 , as well as between the overall effectiveness and that in stage 2. Nevertheless, the average effectiveness in stage 2 was slightly lower than that in stage 1 during 2010, which was not similar to that in 2000 .

To investigate the difference between the overall effectiveness in 2000 and 2010, it was more appropriate to compare the ranks rather than numerical scores because the models for measuring the different periods used two boundaries, which produced different reference sets, i.e., the calculated driving effectiveness scores in 2000 and 2010 were derived from their specific comparative criteria.

The ranks for the total effectiveness were quite similar in 2000 and 2010 (Table 2). The ranks for the total driving effectiveness in some provinces (municipallities and autonomous regions) changed significantly, i.e., the ranks for Inner Mongolia, Shandong, Henan, Sichuan, Yunnan, and Gansu were 27, 4, 5, 2, 1, and 7 in 2000, respectively, and 2, 23, 26, 21, 19, and 28 in 2010.

Spearman's rank correlation test indicated that the overall effectiveness in the two periods was weakly correlated, with a calculated coefficient of 0.245 compared with the tabulated value of $0.562(n=31, P=$ 0.001). By analyzing the same path, we studied the changes in the indirect and direct driving effectiveness.

For the indirect driving effectiveness, the Spearman's rank correlation coefficient was 0.136 , which was much lower than the tabulated value of 0.562 , thereby indicating a weak correlation. However, there was an opposite trend in the direct driving effectiveness, where the Spearman's rank correlation coefficient of 0.579 was higher than the tabulated value of 0.562 , thereby indicating a relatively strong correlation between the ranks of the direct driving effectiveness calculated for the two periods.

The variances in the three processes were also considered. The values for the overall process, stage 1 , and stage 2 were $0.020,0.065$, and 0.079 , respectively, in 2000 , and $0.018,0.063$, and 0.071 in 2010 . The variance represents the magnitude of the variation among the scores around the mean value. A higher variance indi- cates greater heterogeneity, whereas a lower variance represents more homogeneity in the data. The variance results indicated that the heterogeneity of direct driving effectiveness was highest in 2000 , followed by indirect drivers, and the heterogeneity of the overall driver effectiveness was lowest. In addition, the ranks of the driving effectiveness variances in the two periods were always similar, e.g., the indirect driving effectiveness was ranked second in 2010, which was the same as that in 2010 .

\section{Discussion}

Despite advances in understanding causality in complex forest ecosystem water conservation services, determineing the interactions between these drivers remains a major challenge. We investigated the IN-DI-ESS model (feedback loop B, indicated by double lines with an arrow), but to understand the water conservation function in forest ecosystems, it will be necessary to explore the influence of causal chains comprising more than two sub-processes, i.e., the extended IN-DI-ESS model, indirect-direct-ecosystem service-ecosystem impact-human response (IN-DI-ESS-EI-HR) framework (feedback loop $\mathrm{A}$, indicated by dotted lines with an arrow), or its shortcut format indirect-direct-ecosystem-human wellbeing (IN-DI-ESS-HB) framework (feedback loop C, indicated by solid lines with an arrow) (Amado, 2003). In addition, there are almost always multiple interacting driving forces, so a one-to-one linkage between particular driving forces and particular changes in ecosystems rarely exists. Multiple interacting drivers cause changes in ecosystem services and create a feedback loop involving the drivers of changes in ecosystem services (Fig. 4). Thus, it is important to extend this idea to include situations where the outputs from the second stage can be fed back as inputs into the first stage of the DEA model. The formulation of the two-stage DEA could be extended to systems with multiple stages connected in series, where the effectiveness of the overall process is the product of the effectiveness of individual sub-processes.

Analyzing the direct drivers is the first step toward defining a policy, but not the solution. The indirect driving forces that underlie pressures need to be identified and used to derive priorities for policy action, although directly addressing certain pressures might be 


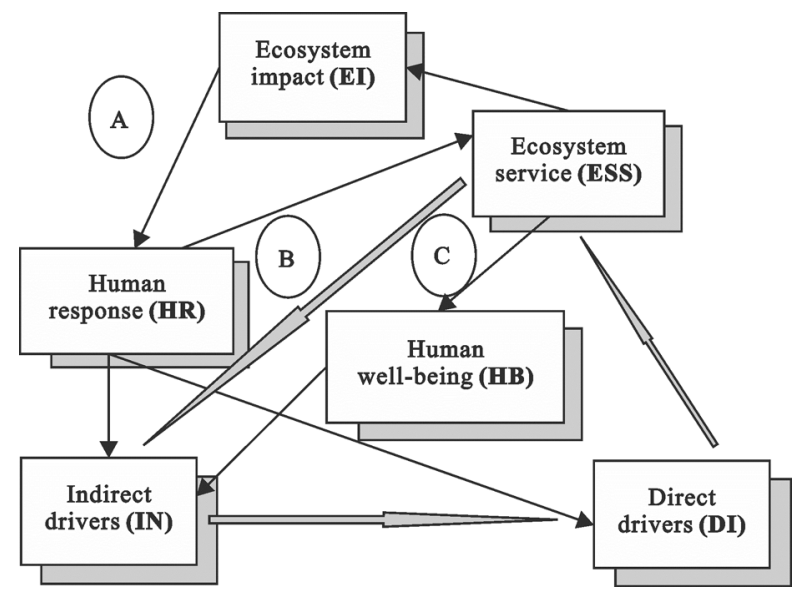

Fig. 4 Causal feedback loop for ecosystem service change

necessary as a type of emergency relief in particularly critical impact situations (Spangenberg, 2007).

Considering the functional interdependencies between and among the indirect and direct drivers of change, the two-stage DEA can also be extended to a complex formulation with feedback because the driving route of ecosystem service change is a process where the outputs from the first stage are intermediate variables that serve as inputs for the second stage (Liang, 2011). There are functional interdependencies between and among the indirect and direct drivers of change, and thus changes in ecological services lead to feedback to the drivers of changes in ecological services. Synergetic driver combinations are very common.

\section{Conclusions}

Drivers are often defined as natural or human-induced factors that directly or indirectly cause change. The driving factors are complex and varied in forest ecosystem water conservation services. Thus, it is essential to identify the main driving forces of change in forest ecosystem water conservation services and to evaluate their effectiveness. The drivers of water conversation change have been discussed widely in previous studies, but some important issues have not been explored previously. As a research topic, the problem of decomposing the drivers of water conversation services has been investigated rarely. A two-stage process concept has been applied infrequently in some previous studies of the effectiveness of drivers. The approach proposed in the present study allows the black-box comprising the driver measurement process to be assessed, thereby pro- viding a new option for measuring the effectiveness of drivers. The results of this study may help managers to improve the effectiveness of forest water conversation services.

Our findings can be summarized briefly as follows. First, four indirect factors (population density, per capita GDP, irrigation efficiency, and per capita food consumption) and six direct factors (precipitation, farmland into forestry or pasture, forest cover, habitat area, water footprint, and wood extraction) are the most critical driving factors with positive or negative impacts on forest ecosystem water conservation services. Second, 31 provinces, municipalities and autonomous regions had a lower average indirect driving effectiveness compared with the direct driving effectiveness in 2000, whereas the average indirect driving effectiveness was higher than the direct driving effectiveness in 2010. This suggests that managers should have paid more attention to improving the macro-social economic environment of forest ecosystem water conversation services in 2000, whereas specific ecological management measures needed to be prioritized in 2010. Third, the two-stage DEA model was used to estimate the effectiveness of forest ecosystem water conservation services, thereby explicitly defining the physical relationship between the overall causal chain of drivers and the component sub-processes, but this also produced reliable results in terms of the effectiveness measurement. This innovative effectiveness measurement can locate weak regions so appropriate efforts can be made to improve their effectiveness. For example, if the two-stage DEA model shows that inefficiency is linked mainly to stage 1 , then a decision maker might improve the indirect drivers by adjusting the demographic and economic policies associated with them.

Future research might use network DEA techniques to examine the effectiveness of drivers of forest water conversation services with internal structures. The internal network structures range from a simple two-stage process to a complex system, where multiple divisions are linked together by intermediate measures. The network DEA approach can help decision makers to understand the system under evaluation by opening the DEA transformation 'black box'. We also hope that the models and methods implemented in this study can facilitate related research in other ecosystem service areas. 


\section{References}

Amado C F, 2003. Exploring the Use of Data Envelopment Analysis for Evaluation in Primary Care. Coventry: The University of Warwick.

Asdak C, Jarvis P G, Van Gardingen P et al., 1998. Rainfall interception loss in unlogged and logged forest areas of Central Kalimantan, Indonesia. Journal of Hydrology, 206(3-4): 237-244. doi: 10.1016/S0022-1694(98)00108-5

Banker R D, Charnes A, Cooper W W et al., 1989. An introduction to data envelopment analysis with some of its models and their uses. In: Chan J L(eds.). Research in Government and Nonprofit Accounting, 5: 125-163.

Bosch J, Hewlett J A, 1982. A review of catchment experiments to determine the effect of vegetation changes on water yield and evapotranspiration. Journal of Hydrology, 55(1-4): 3-23. doi: 10.1016/0022-1694(82)90117-2

Brown A E, Zhang L, McMahon T A et al., 2005. A review of paired catchment studies for determining changes in water yield resulting from alterations in vegetation. Journal of Hydrology, 310(1-4): 28-61. doi: 10.1016/j.jhydrol.2004.12.010

Charnes A, Cooper W W, Rhodes E, 1978. Measuring efficiency of decision making units. European Journal of Operational Research, 2(6): 429-444. doi: 10.1016/0377-2217(78)90138-8

Chertow M R, 2000. The IPAT equation and its variants: Changing views of technology and environmental impact. Journal of Industrial Ecology, 4(4): 13-29. doi: 10.1162/108819800525 41927

CMWR (China's Ministry of Water Resources). China Water Resources Bulletin in 2000/2010. Beijing: China Water Conservancy and Hydropower Press, 2001; 2011. (in Chinese)

Crockford R, Richardson D, 2000. Partitioning of rainfall into throughfall, stemflow and interception: effect of forest type, ground cover and climate. Hydrological Processes, 14(16-17): 2903-2920. doi: 10.1002/1099-1085(200011/12)14:16/17<2903

Cronbach L J, 1951. Coefficient alpha and the internal structure of tests. Psychometrika, 16(3): 297-334. doi: 10.1007/BF023 10555

Daniel W W, 1978. Applied Nonparametric Statistics. Boston: Houghton Mifflin,163-176.

Dietz T, Rosa E A, 1994. Rethinking the environmental impacts of population, affluence and technology. Human Ecology Review, 1: 277-300.

Farley K A, Jobbágy E G, Jackson R B, 2005. Effects of afforestation on water yield: a global synthesis with implications for policy. Global Change Biology, 11(10): 1565-1576. doi: 10.1111/j.1365-2486.2005.01011.x

Forester D J, Machlis G E, 1996. Modeling human factors that affect the loss of biodiversity. Conservation Biology, 10(4): 1253-1263. doi: 10.1046/j.1523-1739.1996.10041253.x

Geist H J, Lambin E F, 2001. What Drives Tropical Deforestation? A Meta-Analysis of Proximate and Underlying Causes of Deforestation Based on Subnational Case Study Evidence. Louvain-la-Neuve (Belgium): LUCC International Project Of- fice, LUCC Report Series No. 4, 6-15.

Geist H, Lambin E, 2002. Proximate causes and underlying driving forces of tropical deforestation. Bioscience, 52(2): 143-150. doi: 10.1641/0006-3568(2002)052

Golany B, Roll Y, 1989. An application procedure for DEA. OMEGA, 17(3): 237-250. doi: 10.1016/0305-0483(89)90029-7

Jabbour J, Hunsberger C, 2014. Visualizing relationships between drivers of environmental change and pressures on land-based ecosystems. Natural Resources, 5: 146-160. doi: 10.4236/nr. 2014.54015

Jetten V, 1996. Interception of tropical rain forest: performance of a canopy water balance model. Hydrological Processes, 10(5): 671-685. doi: 10.1002/(SICI)1099-1085(199605)10:5<671

Kao C, Hwang S N, 2008. Efficiency decomposition in two-stage data envelopment analysis: an application to non-life insurance companies in Taiwan. European Journal of Operational Research, 185 (1): 418-429. doi: 10.1016/j.ejor.2006.11.041

Kelble C R, Loomis D K, Lovelace S et al., 2013. The EBMDPSER conceptual model: integrating ecosystem services into the DPSIR ftramework. Plos One, 8(8): 1-12. doi: 10.1371/ journal.pone. 0070766

Krishnaswamy J, Bonell M, Venkatesh B et al., 2013. The groundwater recharge response and hydrologic services of tropical humid forest ecosystems to use and reforestation: support for the 'infiltration-evapotranspiration trade-off hypothesis'. Journal of Hydrology, 498(19): 191-209. doi: /10.1016/j.jhydrol. 2013.06.034

Lambin E F, Turner B L, Geist H J et al., 2001. The causes of land-use and land-cover change: moving beyond the myths. Global Environmental Change, 11(4): 261-269. doi: 10.1016/ S0959-3780(01)00007-3

Liang L, Zhao Q L, Wade D Cook et al., 2011. Data envelopment analysis efficiency in two stage networks with feedback. IIE Transactions, 43(5): 309-322. doi: 10.1080/0740817X.2010. 509307

Maes W H, Heuvelmans G, Muys B, 2009. Assessment of land use impact on water-related ecosystem services capturing the integrated terrestrial-aquatic system. Environmental Science \& Technology, 43(19): 7324-7330. doi: 10.1021/es900613w

Mashayekhi Z, Panahi M, Karami M et al., 2010. Economic valuation of water storage function of forest ecosystems (case study: Zagros Forests, Iran). Journal of Forestry Research, 21(3): 293-300. doi: 10.1007/s11676-010-0074-3

McCay B J, Jentoft S, 1998. Market or community failure? Critical perspectives on common property research. Human Organization, 57(1): 21-29. doi: 10.17730/humo.57.1.372712415 k227u25

Nardo M, Saisana M, Saltelli A et al., 2005. Tools for Composite Indicators Building. Ispra: Joint Research Center of the European Commission.

Nardo M, Saisana M, Saltelli et al., 2008. Handbook on Constructing Composite Indicators: Methodology and User Guide. Paris: OECD Publishing

NBSC (National Bureau of Statistics of China). Statistical Yearbook of China in 2000/2010. Beijing: China Statistics Press, 
2001; 2011. (in Chinese)

Notter B, Hurni H, Wiesmann U, Abbaspour K C, 2012. Modelling water provision as an ecosystem service in a large East African river basin. Hydrological and Earth System Science, 16: 69-86. doi: 10.5194/hess-16-69-2012

Nunez D, Nahuelhual L, Oyarzun C, 2006. Forests and water: the value of native temperate forests in supplying water for human consumption. Ecological Economics, 58(3): 606-616. doi: 10.1016/j.ecolecon. 2005.08.010

O'Connor J, 1988. Capitalism, nature, socialism: a theoretical introduction. Capitalism, Nature, Socialism, 1(1): 11-38. doi: 10.1080/10455758809358356

OSFCDRH (Office of State Flood Control and Drought Relief Headquarters). Bulletin of Flood and Drought Disaster in China 2000; 2010. Beijing: China Water Conservancy and Hydropower Press, 2001; 2011. (in Chinese)

Palloni A, 1994. The Relation between Population and Deforestation: Methods for Drawing Causal Inferences from Macro and Micro Studies. Colorado: Westview Press.

Rudel T, Roper J, 1996. Regional patterns and historical trends in tropical deforestation, 1976-1990: a qualitative comparative analysis. Ambio, 25(3): 160-166.

Spangenberg J H, 2007. Biodiversity pressure and the driving forces behind. Ecological economics, 61: 146-158. doi: 10. 1016/j.ecolecon.2006.02.021

Spangenberg J H, Görg C, Truong D T et al., 2014. Provision of ecosystem services is determined by human agency, not ecosystem functions: four case studies. International Journal of Biodiversity Science, Ecosystem Services \& Management, 10(1): 40-53. doi: 10.1080/21513732.2014.884166

Stern D I, 1998. Progress on the environmental Kuznets curve? Environment and Development Economics, 3(2): 173-196.

Sun G, Zhou G, Zhang Z et al., 2006. Potential water yield reduc- tion due to forestation across China. Journal of Hydrology, 328(3-4): 548-558. doi: 10.1016/j.jhydrol.2005.12.013

UNEP, 2005a. Millennium Ecosystem Assessment. Ecosystems and Human Well-Being: Synthesis. Washington, DC: Island Press.

UNEP, 2005b. Millennium Ecosystem Assessment. Ecosystems and Human Well-Being: Current State and Trends. Washington, DC: Island Press.

UNEP, 2005c. Millennium Ecosystem Assessment. Ecosystems and Human Well-Being: Scenarios. Washington, DC: Island Press.

UNEP, 2005d. Millennium Ecosystem Assessment Ecosystems and Human Well-Being: Policy responses. Washington, DC: Island Press.

UNEP, 2005e. Millennium Ecosystem Assessment. Ecosystems and Human Well-Being: Multiscale Assessments. Washington, DC: Island Press.

Verma J P, 2013. Data Analysis in Management with SPSS Software. German: Springer, 368-382.

Villa F, Voigt B, Erickson J D, 2014. New perspectives in ecosystem services science as instruments to understand environmental securities. Philosophical Transactions of the Royal Society B: Biological Sciences, 369(1639): 1-15. doi: 10.1098/ rstb.2012.0286

Vose J M, Sun G, Ford C R et al., 2011. Forest ecohydrological research in the 21 st century: what are the critical needs? Ecohydrology, 4(2): 146-158. doi: 10.1002/eco.193

Waggoner P E, Ausubel J H, 2002. A framework for sustainability science: a renovated IPAT identity. Proceedings of the National Academy of Sciences, 99(12): 7860-7865. doi: 10.1073/pnas. 122235999

White L J, 1967. The historical roots of our ecological crisis. Science, 155(3767): 1203-1207. doi: 10.1126/science.155.3767.1203 